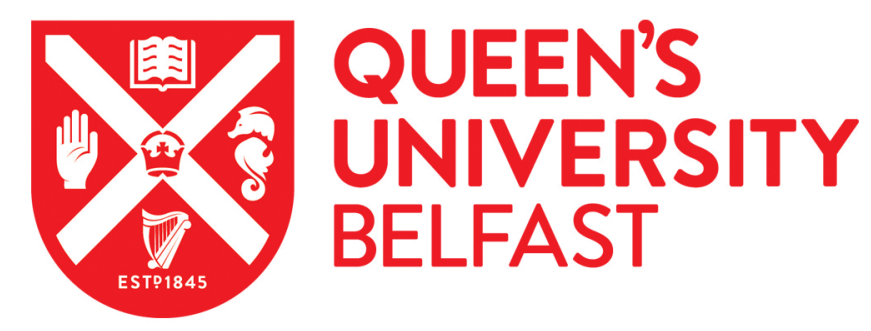

\title{
Steady-State and Transient Performance of Biodiesel-Fueled Compression-Ignition-Based Electrical Generation
}

Best, R. J., Kennedy, J. M., Morrow, D. J., \& Fox, B. (2011). Steady-State and Transient Performance of Biodiesel-Fueled Compression-Ignition-Based Electrical Generation. IEEE Transactions on Sustainable Energy, 2(1), 20-27. https://doi.org/10.1109/TSTE.2010.2085458

Published in:

IEEE Transactions on Sustainable Energy

Document Version:

Peer reviewed version

Queen's University Belfast - Research Portal:

Link to publication record in Queen's University Belfast Research Portal

Publisher rights

Copyright 2010, IEEE.

This work is made available online in accordance with the publisher's policies. Please refer to any applicable terms of use of the publisher.

\section{General rights}

Copyright for the publications made accessible via the Queen's University Belfast Research Portal is retained by the author(s) and / or other copyright owners and it is a condition of accessing these publications that users recognise and abide by the legal requirements associated with these rights.

Take down policy

The Research Portal is Queen's institutional repository that provides access to Queen's research output. Every effort has been made to ensure that content in the Research Portal does not infringe any person's rights, or applicable UK laws. If you discover content in the Research Portal that you believe breaches copyright or violates any law, please contact openaccess@qub.ac.uk. 


\title{
Steady-State \& Transient Performance of Biodiesel Fuelled Compression Ignition Based Electrical Generation
}

\author{
R. J. Best, Member, IEEE, J. M. Kennedy, D. J. Morrow, Member, IEEE, and B. Fox
}

\begin{abstract}
This paper investigates the performance characteristics of rapeseed methyl ester, EN 14214 biodiesel, when used for electrical generation in compression ignition engines. The work was inspired by the need to replace fossil diesel fuel with a sustainable low carbon alternative while maintaining generator performance, power quality and compliance with ISO 8528-5. A $50 \mathrm{kVA}$ Perkins diesel engine generator was used to assess the impact of biodiesel with particular regard to gen-set fuel consumption, load acceptance and associated standards. Tests were performed on the diesel gen-set for islanded and grid-connected modes of operation, hence both steady-state and transient performance were fully explored. Performance comparisons were made with conventional fossil diesel fuel, revealing minimal technical barriers for electrical generation from this sustainable, carbon benign fuel. Recommendations for improved transient performance are proposed and validated through tests.
\end{abstract}

Index Terms-Biodiesel, Diesel-Driven Generators, Distributed Generation, Real-Time Control, Sustainability, Transient Response.

\section{INTRODUCTION}

$\mathrm{E}$ LECTRICITY is the fastest growing form of end-use energy globally, representing an increasing share of projected worldwide energy consumption up to 2030 [1]. One reason for the increase is the electrification of the heat and transport sectors, which can subsequently avail of electrical energy generated from renewable sources like wind. In addition, conventional thermal generators are becoming more efficient, so the net effect is a cleaner, more sustainable electric power industry. It is also accepted that the increased electrification of the heat and transport sector will outweigh energy efficiency measures increasingly adopted by domestic and industrial consumers, such that the trend is a steady growth in system demand.

Under the traditional planning approach, significant increases in electrical load would instigate the reinforcement or

R. J. Best would like to thank the EPSRC Supergen V, UK Energy Infrastructure (AMPerES) grant in collaboration with UK electricity network operators working under Ofgem's Innovation Funding Incentive scheme; full details on http://www.supergen-amperes.org. J. M. Kennedy would like to thank the Science Foundation Ireland (SFI) for funding this work through the Charles Parsons Energy Research Award.

R. J. Best, J. M. Kennedy, D. J. Morrow, and B. Fox are with the Electrical Power and Energy Research Cluster, Queen's University Belfast, Belfast BT9 5AH, Northern Ireland (e-mail: r.best@qub.ac.uk; jason.kennedy@qub.ac.uk; dj.morrow@ee.qub.ac.uk; b.fox@ee.qub.ac.uk). construction of both new transmission lines and generation capacity to meet this demand. However, in the developed world the lead time for individual transmission reinforcement is typically 7 to 10 years [2]. Indeed, in developed countries, the design and build of new lines, which require new rights-ofway, may in some cases be blocked completely by planning restrictions, due to green belts and conservation areas. Subsequently, delays and restrictions on new transmission capacity, growth of intermittent renewable generation, and increasing electrical load are all pushing the power system into uncharted territory.

This paper considers the use of fast flexible distributed generation, located near to the load centres, as a means to help balance generation and demand in this new environment. Typically this generation has a diesel fuelled ignition based compression engine as a prime mover and is referred to as a genset. Gen-sets have traditionally been used for stand-by power generation in hospitals, offices, telecoms, schools, retail and financial sectors along with many other applications where there is no available site supply [3]. In the latter case, with no site supply, the function of gen-sets is a prime power application. This is frequent in remote locations or third world regions. Diesel gen-sets are also frequently used by large electrical consumers for peak shaving and peak lopping applications, in order to avoid expensive electricity [4]. Peak lopping and peak shaving are, by definition, carried out for the periods of maximum demand in the respective power system. Within the Northern Ireland power system for example, there is $132 \mathrm{MW}$ of distributed diesel generation [5], operating between 4 - 7 pm on weekdays of the winter months (November to February). This capacity could supply over $6.9 \%$ of the 1905 MW peak system demand [6].

In addition to peak lopping and peak shaving, there are schemes throughout the world where distributed diesel gensets are remotely controlled by network operators to provide emergency system reserve. Wessex water in the UK, for example, own and operate 550 gen-sets, with a total capacity exceeding $100 \mathrm{MW}$. Out of this capacity, $18 \mathrm{MW}$ is contracted to National Grid for a fast reserve service, available no later than 20 minutes after the tripping of a large thermal unit [7]. Given the growth of variable and uncertain renewable generation, such as wind power, the need for fast flexible generation is apparent, in order to maintain security of supply. The total capacity of distributed diesel plant that could be applied to 
such a scheme is believed to be over $20 \mathrm{GW}$ for the UK [8], which is very significant in the context of a peak demand of $60 \mathrm{GW}$, and much larger than the reported 2009 installed wind capacity of $4 \mathrm{GW}[9]$.

These factors suggest that existing flexible generation will be a valuable commodity in the near future and, as such, owners of diesel generation would be well placed to offer additional or ancillary services and thus more fully utilize their capital investment. This is especially true for generation which is located close to load centres and can therefore provide voltage support, reduce power flows on critical transmission lines and hence improve security of the system.

Associated with the use of diesel gen-sets are, however, the emissions of particulate matter, carbon dioxide, carbon monoxide and volatile organic compounds. Such emissions detract from the suitability and public acceptance. Given the need for flexible generation located close to load centres and the capacity of diesel generation already in existence, it makes sense to consider how the performance of such generation can be improved. Therefore, this paper considers the performance of gen-sets fuelled on biodiesel, a less carbon dependent fuel, with lower emissions of particulate matter, carbon monoxide and volatile organic compounds.

\section{OVERVIEW OF BIODIESEL}

Biodiesel is a carbon benign alternative to fossil diesel that is manufactured from vegetable oils, recycled cooking oils, or animal fats. Plants produce oils from sunlight and air, and can do so year after year on cropland, therefore these oils are renewable. Animal fats are, by way of the food chain, derived from photosynthesis, so they too are renewable. Carbon is absorbed from the atmosphere as the fuel crop grows through the process of photosynthesis. This carbon is later released during combustion of the fuel end-product. The net addition of carbon to the atmosphere is therefore smaller than when compared with fossil diesel. On the other hand, combustion of fossil diesel adds carbon to the atmosphere that has been sequestered in the earth's crust over millions of years, and will not be removed in a human lifetime. It is appropriate to remark that Rudolph Diesel famously demonstrated his early diesel engine using peanut oil, and that he himself envisaged a future of biomass derived fuel for his engine. In Europe biodiesel is primarily made from rapeseed oil (canola) producing rapeseed methyl ester (RME), whereas in North America soybean is the dominant feedstock. In some countries, such as France, small quantities of biodiesel are also made from sunflower oil.

Biodiesel is competitive with fossil diesel in most technical aspects and also delivers several distinct advantages compared with fossil diesel [10, 11]:

- Derivation from a renewable domestic resource, thus reducing dependence on and preserving oil reserves.

- Biodegradability (degrades $98 \%$ in 21 days, compared with $50 \%$ for fossil diesel). Therefore biodiesel is often used in national parks and sensitive conservation areas where the impacts of fuel spillages must be mitigated [12].
- Reduction of most exhaust emissions (with the exception of nitrogen oxides).

- Higher flash point, leading to safer handling and storage.

- Excellent lubricity. A biodiesel additive of 1-2\% can completely restore the lubricating properties associated with the use of low sulphur diesel, which is increasingly adopted to meet emission targets.

- A reduction in net carbon life-cycle emissions compared with fossil diesel.

The energy density of fossil diesel [13] is $42.47 \mathrm{MJ} / \mathrm{kg}$ and that of biodiesel is $37.417 \mathrm{MJ} / \mathrm{kg}$. The assumed densities of the fuels are $0.84 \mathrm{~kg} / \mathrm{l}$ for fossil diesel and $0.89 \mathrm{~kg} / \mathrm{l}$ for biodiesel. Given this, the mass density $(\mathrm{kg} / \mathrm{l})$ ratio of biosiesel to fossil diesel is 1.060 , whereas the energy density $(\mathrm{MJ} / \mathrm{l})$ ratio is 0.933 . Thus, biodiesel contains approximately $7 \%$ less energy by volume than typical fossil diesel fuel in the UK and $12 \%$ less energy by mass [10]. All biodiesels, regardless of feedstock, have similar energy densities, but noticeable differences in color.

With regard to sustainability and ethical land use, the credentials of biodiesel have been severely scrutinized in recent years. The conclusions from the more authoritative reports are that with careful land and process management, biodiesel production can displace a small fraction of fossil diesel consumption while providing a net carbon saving, without adverse environmental consequences [14]. The study in [15] finds that replacing gen-set fossil diesel consumption with a $100 \%$ blend (B100) of biodiesel mitigates $78 \%$ of life-cycle diesel fuel carbon dioxide emissions.

\section{A. Biodiesel and Human Health}

The emissions from diesel fuel combustion contain hundreds of different polycyclic aromatic hydrocarbons (PAHs) and mono-aromatic hydrocarbons (MAHs). These emissions are suspected of causing cancer and other life threatening illnesses [16]. The main sources of PAHs and MAHs in diesel exhaust are unburned molecules from fuel, pyro-synthesis and structural modifications during combustion. Biodiesel is free from aromatic compounds and sulphur [17] and therefore has the potential to reduce carcinogenic emissions. Table $1 \mathrm{com}-$ pares the emissions of biodiesel, made from various sources, with conventional fossil based ultra-low sulphur diesel (ULSD) [18].

Table 1 shows that biodiesel made from waste vegetable oil delivers the greatest reduction in life-cycle emissions of carbon monoxide, volatile organic carbon and particulate matter when compared with ULSD. The nitrogen oxide (NOx) emissions are however seen to increase. Machinery in mines is often switched to use biodiesel blends, as it is believed to reduce the risk of illness and life-threatening diseases. Such factors suggest that replacing fossil diesel with biodiesel in electrical generators, located close to residential areas, would reduce the impact of emissions in the immediate environment and hence the impact on human health would also be reduced. 
TABLE I

PERCENTAGE CHANGE IN FULL LIFE-CYCLE AIR POLLUTANT EMISSIONS FOR $100 \%$ BIODIESEL COMPARED WITH ULTRA-LOW SULFUR FOSSIL DIESEL [18]

Change in pollutant compared $\quad$ B100 from $\quad$ B100 from $\quad$ B100 from waste with ULSD Rapeseed tallow cooking oil

\begin{tabular}{llll}
\hline Carbon monoxide (CO) & -27 & -37 & -47
\end{tabular}

$\begin{array}{llll}\text { Nitrogen oxides (NOx) } & +17 & +15 & +4\end{array}$

Volatile organic carbon (VOC) $\quad-26 \quad-29 \quad-45$

Particulate matter (PM)

coking oil

$+4$

$-23$

\section{B. Drawbacks of Biodiesel}

Biodiesel has less favorable cold flow properties compared to conventional diesel. Unlike petroleum, fossil diesel and biodiesel can both start to freeze or gel as it gets colder. At low temperatures the long chain molecules of methyl ester in biodiesel align and eventually bond into a crystalline structure. This happens more readily in biodiesel than in fossil diesel. If biodiesel begins to gel, it can clog filters or may eventually become too thick to be pumped from the fuel tank to the engine.

Analysis of biodiesel samples, from various sources in the UK, highlight considerable variation in $\mathrm{B} 100$ pour point ranging from $4^{\circ} \mathrm{C}$ to $-14^{\circ} \mathrm{C}$. A pour point of $4^{\circ} \mathrm{C}$ would present cold weather difficulties in many climates and would need cold weather additives if used neat. For stationary gen-sets operating in a peak lopping or peak shaving role, fuel gelling can be prevented with a simple tank heater and thermostat. This does, however, rely on the availability of a mains supply for energy.

Biodiesel has been shown to increase NOx emissions in many unmodified engines. NOx are created when nitrogen in the intake air reacts with oxygen at the higher in-cylinder combustion temperatures. As with fossil-based diesel fuel, the exact composition of the biodiesel will influence NOx emissions. To reduce NOx emissions, engine manufacturers are developing new biodiesel fuel additives to combat the problem. For a generator fuelled on B20, [19] demonstrates that a suitable fuel additive can increase power density while reducing exhaust emissions and fuel consumption. Retarding the engine fuel injection timing has also been found to mitigate this problem [20]. More work is, however, required in this area to consider higher concentration blends of biodiesel.

The application of biodiesel in electrical generation is significantly different from transportation due to the requirement for constant gen-set engine speed and highly specified load acceptance. Such tolerances place extreme demands on the technology and fuelling systems. This paper therefore investigates the operation of a diesel gen-set when fuelled on both fossil diesel and B100 (100\%) biodiesel, with particular focus on the electrical characteristics of the generator, and hence implications for appropriate generator rating to meet a specific load and load step requirement.

\section{EXPERIMENTAL TEST BED}

Fig. 1 shows a diagram of the experimental test bed, consisting of a $50 \mathrm{kVA}$ Perkins diesel engine gen-set, with diverter fuel valves to switch between regular fossil diesel and B100 biodiesel. Its standby power rating is $40 \mathrm{kWe}$ and the prime power (continuous) rating is $36 \mathrm{kWe}$. This gen-set has a 4-

stroke, $1500 \mathrm{rpm}, 3.99$ litre engine with a compression ratio of 16.0:1, and is typical of a unit used by industry for emergency standby generation or peak shaving. The gen-set can operate using the factory fitted governor and automatic voltage regulator (AVR) or can be switched to follow control algorithms implemented in Mathworks xPC Target. In order to accept biodiesel as a fuel source, the gen-set required the retrofit of a biodiesel compatible fuel injection pump.

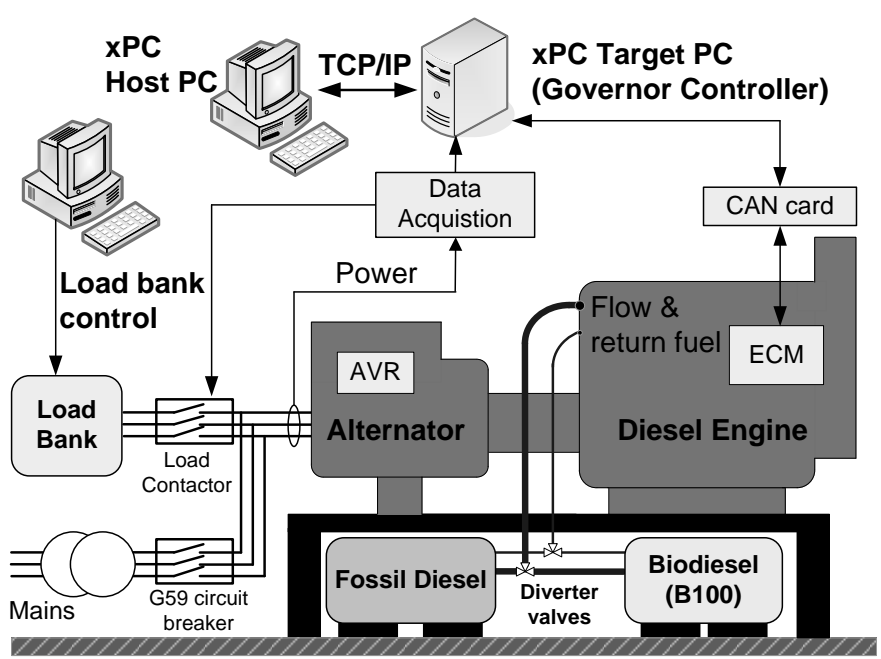

Fig. 1. Diagram of test bed configuration

Both grid-connected and isolated modes of operation are available.

Grid-connection is facilitated by an appropriate control panel, G59 protection relay (as required in the United Kingdom), and use of an AVR with droop current transducer.

During isolated operation the mains circuit breaker is disconnected and the analogue speed set-point from the control panel to the engine control module (ECM) is overridden by a speed or fuel command provided by the XPC target PC based governor. Communication between the xPC target PC and ECM is performed using controller area network (CAN) messages. A load bank allows various loads to be added to the engine in discrete steps, after which the response of the generator can be monitored.

The xPC target PC interface is also used to measure and record the engine control parameters along with the alternator electrical output. A Canape XL log software module is used to read the appropriate CAN bus register values. This module provides access to fuel consumption, engine speed, fuel temperature, desired fuel injection, final fuel injection, and injection timing angle with respect to engine top-dead-centre.

\section{STEADY-STATE OPERATION}

\section{A. Grid-Connected Operation}

A grid-connected gen-set will normally be operated near its maximum continuous real power output, as this leads to more efficient use of the gen-set.

The gen-set was connected to the grid and supplies a constant power output of $30 \mathrm{~kW}, 75 \%$ of rated load $(50 \mathrm{kVA}$ with a power factor of 0.8 ). Initially the gen-set is fuelled with fossil diesel, then after 30 minutes the fuel type was switched to 
$100 \%$ biodiesel without stopping the engine. The fuel injection quantity is seen to increase from $76.3 \%$ to $81.6 \%$ of maximum fuelling rate. This represents a $7 \%$ increase, with respect to the fossil diesel fuelling, and is a result of the reduced energy content of biodiesel compared with fossil diesel. Fig. 2 shows the two periods of operation. In this test the electrical power produced is unaffected by the switch from fossil diesel to biodiesel. The engine temperature also remains stable throughout.

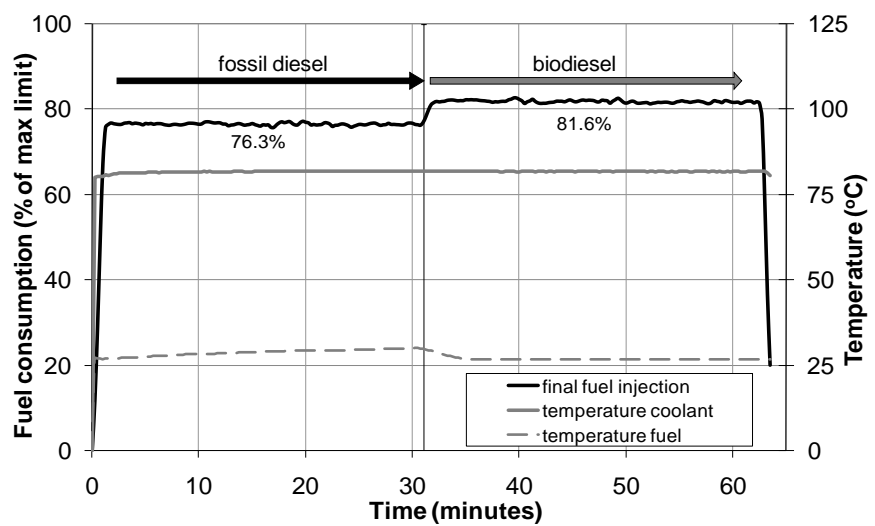

Fig. 2. $30 \mathrm{~kW}$ operation back-to-back with seamless changeover from fossil diesel to biodiesel

The power reference is increased until the governor reaches its maximum fuel injection quantity. The maximum power that can be extracted from the machine on conventional diesel is $40.8 \mathrm{~kW}$. Repeating the test with biodiesel the governor again reaches its fuel injection quantity limit, but the electrical power is reduced to $37.4 \mathrm{~kW}$.

These steady-state tests show that biodiesel reduces the maximum power capability of the generator by $8 \%$ at full load. Although this reduction is noticeable, the efficiency is not adversely affected and it would not prevent feasible operation of diesel gen-sets in a grid supporting role. If such gensets were deployed in a grid supporting role the only consequence would be a need for slightly more participating units.

\section{B. Steady-State Fuel Efficiency}

The efficiency of the $50 \mathrm{kVA}$ gen-set was calculated at different loads, as the ratio of the mechanical energy of the engine output to the stored energy in the fuel. Energy and mass density of the fuels are assumed to be those from section II. The speed is constant, at $1500 \mathrm{rpm}$, and the engine is at normal operating temperature. No-load, steady speed losses (friction, windage, engine and alternator auxiliaries) are estimated at $4 \mathrm{~kW}$, and electrical load related losses equivalent to 0.3 $\Omega /$ phase at $415 \mathrm{~V}$ are used, representing parasitic stator resistance and rotor excitation current.

The efficiency for the two fuels is shown in Fig. 3. It should be noted that this form of distributed generation has efficiencies which exceed much of the older fast-start open cycle gas turbine plant installed in the UK [21].

From Fig. 3 it is immediately obvious that there is not a straightforward relationship between efficiency and electrical load, or between the efficiencies with the two fuels. These differences cannot be interpreted without first understanding the engine's fuel injection timing strategy and the effect that biodiesel's physical properties have on this.

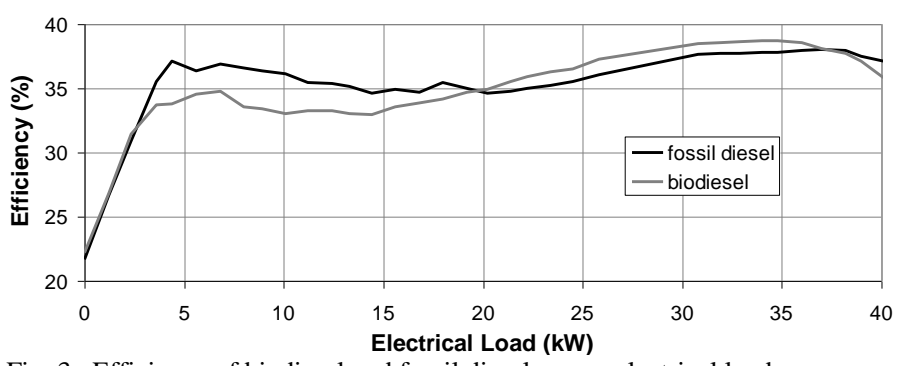

Fig. 3. Efficiency of biodiesel and fossil diesel versus electrical load

\section{Start-of-Injection Timing}

The fuel injection strategy of this engine involves a variable, or dynamic, start-of-injection. The start-of-injection timing in engines is generally calibrated to obtain a balance between NOx and particulate matter emissions, while maintaining fuel efficiency. An advanced start-of-injection tends to cause higher temperatures and thus more NOx production, whereas a retarded start-of-injection leads to incomplete combustion of the fuel and increases smoke emissions [22]. The control system dynamically changes injection timing depending on injected fuel quantity, engine temperature and speed. As previously mentioned, gen-sets differ from transportation applications in that they are generally operated at constant speed. In all tests the engine was at normal running temperature, and speed was nominally $1500 \mathrm{rpm}$, not exceeding the range 1200 to $1700 \mathrm{rpm}$ during the largest load disturbances in Section V. Thus the major factor influencing the start-ofinjection timing is the injected fuel quantity.

A basic injection timing control strategy is to advance timing as the injected fuel quantity increases to compensate for a longer injection duration. For small injected fuel quantities, the timing is also advanced. This reduces the amount of smoke produced under light load conditions by keeping the cylinder temperature high, and is at the expense of increasing NOx emissions. The start-of-injection relative to idle is plotted against electrical load in Fig. 4 for nominal gen-set speed and normal operating temperature. A positive angle represents a timing advance.

Biodiesel's physical properties affect the engine's injection timing in the following ways:

\section{1) Advancing injection timing:}

Biodiesel has different physical properties to fossil diesel, such as a higher viscosity and mass density, and the result is an effective advance in injection timing with increasing biodiesel content [23]. This timing advance is the main cause of increased NOx emissions in Table 1. Furthermore, the higher cetane number of biodiesel causes it to ignite sooner, again advancing the timing. Thus, it has been suggested that the static timing should be retarded when using biodiesel [20].

\section{2) Effect on injection timing control strategy}

Although B100 biodiesel has a higher mass density than fossil diesel, it has a lower energy density. This lower energy density affects the dynamic injection timing in the biodiesel fuelled test engine by shifting the characteristic of Fig. 4 to the left. This happens because start-of-injection is determined by the injected fuel quantity, and because the default injection 
timing settings for fossil diesel are used. At higher loads the biodiesel start-of-injection tends to be advanced with regards to fossil diesel and at low or medium loads it is equal to or retarded from that of fossil diesel.

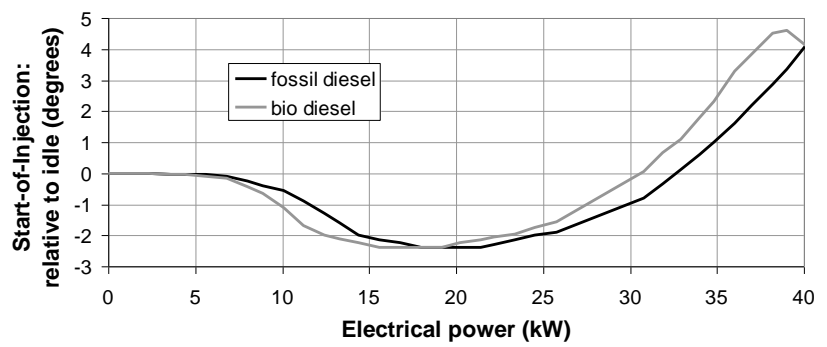

Fig. 4. Start-of-injection versus electrical load characteristic

\section{Interpretation of Steady-State Fuel Efficiency}

The lower energy density of biodiesel has a noticeable effect on the injection timing and, therefore, fuel efficiency. Fig. 3 can now be interpreted by referring to Fig. 4 .

Initially, efficiency rises sharply with increasing electrical load, then falls slightly as load increases from 5 to $15 \mathrm{~kW}$. This correlates to the retardation of start-of-injection in Fig. 4. Biodiesel's start-of-injection is more retarded than fossil diesel's. This appears to have a bearing on biodiesel's performance, as efficiency is particularly low, with fuel consumption being $17 \%$ higher than fossil diesel at $10 \mathrm{~kW}$ load.

Above $15 \mathrm{~kW}$, the efficiency of both fuels begins to rise, and correlates to a start-of-injection advancement with load. Biodiesel start-of-injection is now advanced with respect to fossil diesel and intriguingly, biodiesel has a higher efficiency. Although energy densities reported in the literature were used to calculate efficiency and some error is expected, it is worth noting that at $25 \mathrm{~kW}$ the fuel consumption with biodiesel was only $4 \%$ higher than fossil diesel. This suggests either a higher biodiesel efficiency or an uncharacteristically high energy density. This result must be treated with caution, because although the advanced timing may make the biodiesel fuelled engine more efficient, operation has deviated from the factory calibration, based on fossil diesel, and increased NOx emissions may occur.

Fuel efficiency drops when operating close to maximum load, and is particularly observable for biodiesel. Using the factory settings, the maximum load achievable with biodiesel was $8 \%$ less than with fossil diesel. This is caused by the maximum injected fuel quantity limit and the lower energy density of biodiesel. Only by overriding the injected fuel quantity limit can higher biodiesel power output be achieved; the justification for this will be discussed in Section V. The drop in fuel efficiency at maximum output is either caused by the fuel being injected outside the optimum efficiency window, due to fuel injector limitations, or by exceeding the stoichiometric limit so that there is not enough air available in the combustion chamber to burn all the fuel.

Given the impact of biodiesel's physical properties on the injection control system of this engine, it would be desirable to have fuel specific calibrations. Changing the injection timing was not available, and doing so requires significant expertise regarding the impact on emissions and performance. Further- more, the engine may need to be recertified [10]. With this in mind, alternative controller-based methods of performance enhancement will be considered.

\section{TRANSIENT TESTS: ISOLATED OPERATION}

During isolated operation, whether as emergency standby generation or islanding schemes in future distribution networks, adequate gen-set performance is crucial. The gen-set will be required to operate with varying load, and accept or reject significant load while remaining within operating conditions defined in ISO 8528-5 [24] or otherwise.

An investigation into the transient performance of biodiesel in an isolated system was performed. The test bed is modified accordingly; the mains connection is removed and the load bank in Fig. 1 is used to supply load disturbances. The xPC target $\mathrm{PC}$ based governor can override the analogue signal to the engine control module (ECM) from the synchronisation capable control panel. Furthermore, the xPC target PC based governor can bypass any fuelling limits normally imposed by the ECM. The governor is fixed gain proportional, integral, derivative (PID), and contains anti-windup functionality.

\section{A. Fuel Comparison}

The gen-set transient performance with B100 biodiesel and fossil diesel are compared. In these tests the only change made to the experimental arrangement is the type of fuel.

Fig. 5 (a)-(f) show the frequency transients following $76 \%$ rated load acceptance and rejection $(30.4 \mathrm{~kW})$ along with injected fuel quantity and electric power. Frequency is measured by a magnetic pickup, and the fuel values are returned from the ECM via CAN messages.

Regarding load acceptance, shown in Fig. 5 (a), the fossil diesel performs better than biodiesel in both maximum frequency deviation and settling time. It may be observed in Fig. 5 (c) that the maximum fuel injection quantity limit $(100 \%)$ is reached during load acceptance with both fuels. As expected, the steady-state fuel required with biodiesel is higher than for fossil diesel both before and after the disturbance.

During load rejection, in Fig. 5 (b) and (d), the aim is to rapidly reduce the fuel input. In this case the transient response of the two fuels is similar. The varying power at load acceptance in Fig. 5 (e) is due to the transient voltage caused by the AVR's response. Naturally, no such power transient is observed after load rejection in Fig. 5 (f).

It is interesting to compare fossil diesel and biodiesel transients for different magnitudes of load disturbance. Fig. 6 (a)-(d) show the frequency deviation and $\pm 0.75 \%$ frequency settling time for a range of load acceptances and rejections when fuelling with fossil diesel and biodiesel. In general, the performance of fossil diesel is slightly better. There are several subtle performance differences between the fuels, and these can be attributed, either directly or indirectly, to the lower energy density of biodiesel. 


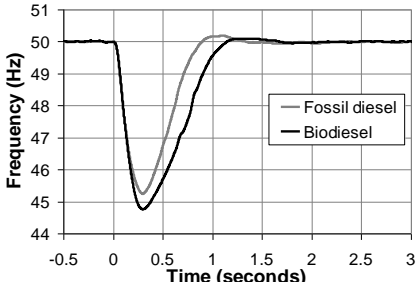

(a)

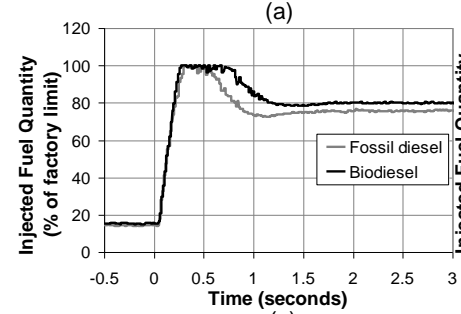

(c)

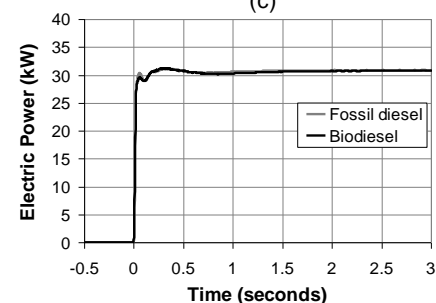

(e)

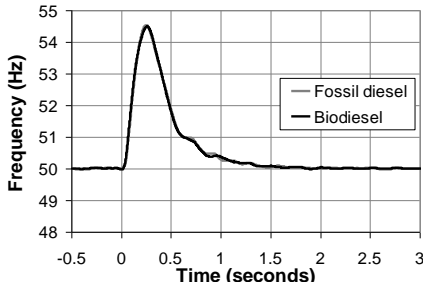

(b)

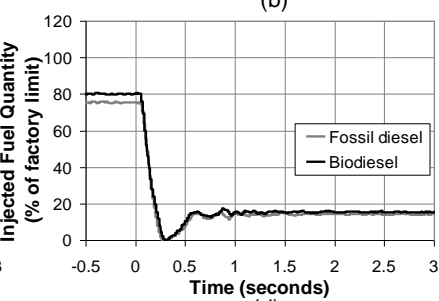

(d)

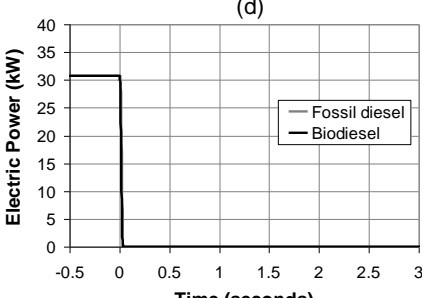

(f)

Fig. 5. Biodiesel and fossil diesel response to $76 \%$ load disturbance. Load acceptance: a) frequency, c) injected fuel quantity, e) electric power; load rejection: b) Frequency, d) injected fuel quantity, f) electric power

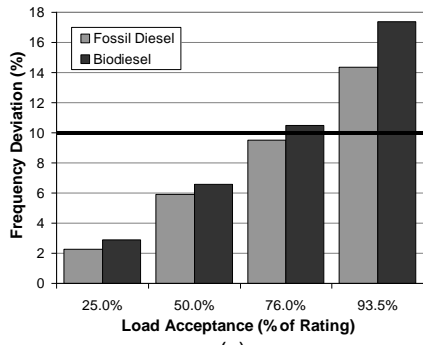

(a)

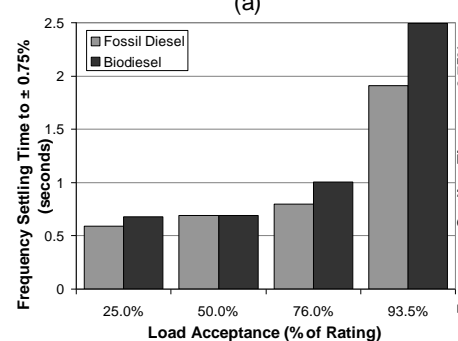

(c)

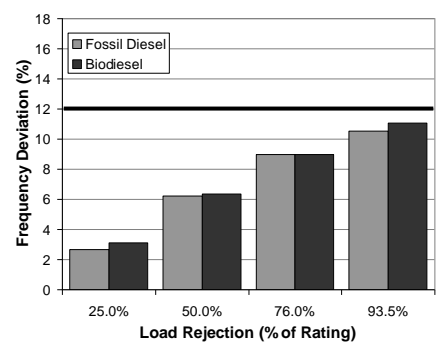

(b)

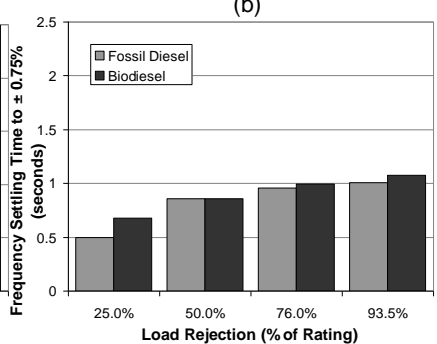

(d)

Fig. 6. Performance of fossil diesel and biodiesel for different load disturbances: (a) Frequency deviation on load acceptance; (b) Frequency deviation on load rejection; (c) Settling time following load acceptance; (d) Settling time following load rejection

In Fig. 6 (a) and (c) the performance degradation caused by the injected fuel quantity limit during the $93.5 \%$ load acceptance is evident. The biggest difference between load acceptance and rejection performance occurs at these large loads. Intriguingly, it is at $50 \%$ load acceptance and rejection that the transient performances exhibit most similarity between fossil diesel and biodiesel. This may be explained by the equal start-of-injection angles and not reaching the fuel injection limit during 50\% load acceptance. At the lowest load disturbance of $25 \%$ load the biodiesel performs comparably worse relative to fossil diesel than at larger magnitudes of load

disturbance. This is particularly evident for load rejection in Fig. 6 (d).

Regardless of fuel, the gen-set passes ISO 8528-5, G2 performance measures [24] for settling to $\pm 0.75 \%$ frequency within 5 seconds of a disturbance, and $100 \%$ load rejection within $12 \%$ frequency deviation. The $-10 \%$ frequency limit during load acceptance is passed for $76 \%$ load with fossil diesel, but a marginal fail with biodiesel.

When considering the implication of these results, it is worth noting that the engine was designed and the governor tuned for optimum performance with fossil diesel fuel, and not biodiesel.

\section{B. Transient Performance Enhancement}

As discussed in section IV, part of the performance difference when using biodiesel can be attributed to the effect that biodiesel's physical characteristics have on the injection process. However, injection timing settings were not modified in the test engine.

Two methods of improving the transient performance are pursued. These are increasing the maximum injected fuel quantity and changing the fixed gains of the governor.

It is important to note that currently and for the near future, constant speed, variable load engines, such as gen-sets, will not be required to pass a transient emissions test $[25,26]$. In the meantime, from the manufacturers' perspective, it is more important to avoid visible transient emissions, that is smoke, which could lead to bad publicity. As particulate emissions from biodiesel are particularly low, see Table 1 [18], biodiesel has an advantage during transient conditions. Thus, there is potential to add the proposed modifications while not exceeding fossil diesel's particulate matter emissions.

\section{1) Transient Increase in Maximum Injected Fuel Quantity}

The fuel injection quantity limit will have an effect on the maximum steady-state power output of the gen-set and on the transient performance during large load acceptances, such as the 93.5\% load acceptance in Fig. 6 (a) and (c). Gen-sets could be de-rated when using fuels that have lower energy density, thus limiting the maximum allowable load step.

The injected fuel quantity limit placed on the engine is intended as a limit for mechanical stress, or a torque limit; to prevent overly high pressure in the combustion chamber; and to maintain a reasonable air to fuel, or stoichiometric, ratio. From the perspective of torque, it would be acceptable to increase the maximum injected fuel quantity when running on biodiesel. It is accepted by the authors that this suggestion may have to be revised if emissions were being considered in detail. Given the current flexibility for transient emissions, it may transpire that when running on biodiesel a temporary increase in injected fuel quantity during a transient would be perfectly acceptable, even if the steady-state injected fuel quantity limit were not to be modified.

The maximum injected fuel quantity was increased by $10 \%$ when using biodiesel. This permits a maximum of $40.8 \mathrm{~kW}$ to be achieved during steady-state. 


\section{2) Governor Tuning}

Conventional governors supply a speed error input to a PID controller and output a fuel value that is then acted upon by the ECM. This method generally requires the fuel-to-power ratio to be constant, which is not the case, especially when the type of fuel is changed and the energy density differs.

The lower energy density of biodiesel suggests that governor gains should be increased in order to achieve a similar controller response. Thus, the controller gain was increased by $6 \%$ when using biodiesel.

\section{3) Improvement Achieved}

The combination of $10 \%$ higher maximum injected fuel quantity and a governor gain increase of $6 \%$ were able to provide an overall improvement in biodiesel transient performance. Significant improvement was observed in the frequency deviation caused by load acceptance, with results shown in Fig. 7. The improvement in the $25 \%$ and $50 \%$ load acceptance was due to the higher controller gain, and in the $76 \%$ and $93.5 \%$ load acceptance was primarily due to increasing the injected fuel quantity limit. The modifications have least effect on the $25 \%$ load acceptance. This can be attributed to the relatively low efficiency of biodiesel at this load range, which cannot be fully compensated by a $6 \%$ increase in governor gain. Increasing the governor gain further would result in instability following the other larger load acceptances. Interestingly, the biodiesel fuelled gen-set now passes ISO 8528-5, G2 for $76 \%$ load acceptance.

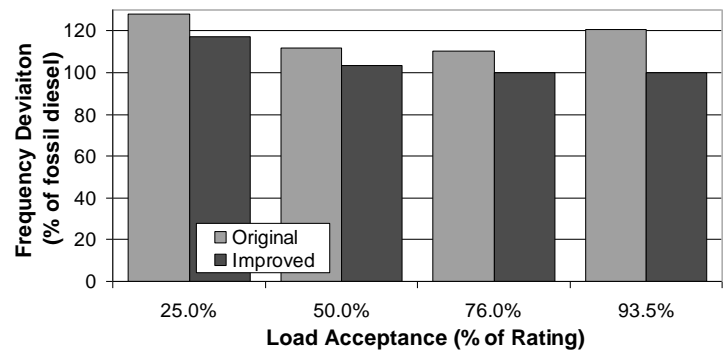

Fig. 7. Load acceptance performance of biodiesel relative to fossil diesel, with and without improvements

\section{RECOMMENDATIONS ON GEN-SET PERFORMANCE WITH B100 BIODIESEL}

- With no control modifications to the governor, ECM or fuel pump, the gen-set should be de-rated by approximately $7 \%$ when using biodiesel.

- Start-of-injection timing maps should be re-tuned for use with biodiesel to maintain optimum performance and regulate emissions. If fuels are interchangeable, this will require some method of online fuel blend determination, such as that described in [27].

- Increase the injected fuel quantity limit to achieve a maximum power output comparable to when the engine is fuelled by fossil diesel and to improve response to large load disturbances. Regarding emissions, it will need to be determined if this is a feasible solution.

- Increase governor gains when using biodiesel, subject to the limits of stability.
- If adjusting the timing is not an option, supplementary governor inputs could be used to improve transient response, adjust for the non-linear relationship of fuel and power, and provide fuel specific governor action. One such option would be the use of a power input signal [28].

\section{CONCLUSION}

With careful land and process management, biodiesel is superior to fossil diesel with regard to sustainability and lifecycle carbon emissions. In addition, the emissions of carbon monoxide, volatile organic carbon and particulates are reduced with biodiesel. These properties make biodiesel a suitable alternative to fossil diesel when used in distributed diesel generation close to residential or environmentally sensitive areas. Biodiesel is also compatible with many modern diesel gen-set engines, and can be used in low blends with those that are not fully compatible.

Disadvantages of biodiesel do however include: a higher pour point, which may requiring pre-heating the stored fuel in colder climates; higher NOx emissions, which may require adjustments to engine timing; and lower power density, leading to increased specific fuel consumption and lower maximum power output. However, biodiesel appears to have comparable, or indeed higher, efficiency with respect to fossil diesel in the power range most likely to be used while grid connected.

This paper has shown that biodiesel can indeed fuel gensets for grid support and power balancing applications. This can add valuable fast, flexible generation to wind dominant power systems, while minimizing the net carbon release. The only consequence, aside from requiring biodiesel compatibility, is that the gen-sets would be de-rated from their fossil diesel ratings, thus requiring slightly more units to participate in the scheme.

During isolated operation, transient response becomes particularly important. Biodiesel's physical characteristics affect operation and efficiency at different load levels. Again, it is biodiesel's lower energy density which impacts most upon transient performance in an unmodified engine. Load rejection is only minimally affected by the change of fuel, with a larger degradation being found in load acceptance.

Transient performance was successfully enhanced by increasing the governor gains and maximum injected fuel quantity. Results comparable with fossil diesel were obtained; however, improvement was not equal across the full range of loads, with the response of small load acceptances from low load remaining particularly poor. It was suggested that this could be improved using a governor power input, or using injection timing settings calibrated for biodiesel.

A number of recommendations for running gen-sets on biodiesel were made. These include de-rating the set by approximately $7 \%$, increasing governor gains and maximum injected fuel quantity, retuning start-of-injection timing maps, and introducing a governor power input. 


\section{REFERENCES}

[1] Energy Information Administration, "International Energy Outlook 2009", Office of Integrated Analysis and Forecasting, U.S. Department of Energy, Washington, DC, May 2009

[2] Department of Communications, Energy and Natural Resources. (2008, Jan.). Analysis of impacts and benefits. All Island Grid Study, Work Stream 4. [Online]. Available: www.dcmnr.gov.ie

[3] N. Jenkins, R. Allen, P. Crossley, D. Kirshen, G. Strbac, Embedded generation, London, UK, The Institute of Electrical Engineers, Power and Energy Series, vol. 31, 2000

[4] K. Pandiaraj, B. Fox, D. J. Morrow, S. Persaud, J. P. Martin, "Centralised control of diesel gen-sets for peak shaving and system support", Proc. Inst. Elect. Eng. Gen., Transm., Distrib., vol. 149, no. 2, pp. $126-$ 132, Mar. 2002

[5] System Operator for Northern Ireland Ltd. (2006, Oct.). Transmission seven year capacity statement 2006. [Online]. Available: http://www.soni.ltd.uk/documents.asp

[6] System Operator for Northern Ireland (SONI). (2008, Nov.). Seven Year Generation Capacity Statement, 2009-2015. [Online]. Available: http://www.soni.ltd.uk/documents.asp

[7] G. Boyle, Ed., Renewable electricity and the grid: the challenge of variability, London, UK, Earthscan, Sep. 2007

[8] G. Boyle, B. Everett, "Department of Trade and Industry energy review consultation 2006: submission by the Open University Energy \& Environment Research Unit", The Open University, Apr. 2006

[9] M. McCaffery (2009, Oct). Real Power, no. 18. BWEA Mag. [Online]. Available: www.bwea.com

[10] G. Knothe, J. V. Gerpen, J. Krahl, The Biodiesel Handbook, Champaign, Ill., USA, AOCS Press, Jan. 2005

[11] P. Gateau, "Twelve years of using 50\% RME fuel mixture in heavy trucks and light vehicles", in Alternative Energies for the Automotive Ind. (AEA), Poitiers, France, Apr. 2006, pp. 1-7

[12] J. C. Pasqualinoa, D. Montanéa, J. Salvadó, "Synergic effects of biodiesel in the biodegradability of fossil-derived fuels", Biomass and Bioenergy, vol. 30, no. 10, Oct. 2006, pp. 874-879

[13] S. Lebedevas, A. Vaicekauskas, G. Lebedeva, V. Makarevicience, P. Janulis, "Change in operational characteristics of diesel engines running on RME biodiesel fuel", Energy \& Fuels, vol. 21, no. 5, 2007, pp. 30103016

[14] G. Stoeglehner, M. Narodoslawsky, "How sustainable are biofuels? Answers and further questions arising from an ecological footprint perspective", Bioresource Technol., 2009, vol. 100, pp. 3825 - 3830

[15] J. Sheehan, V. Camobreco, J. Duffield, M. Graboski, H. Shapouri, "Life cycle inventory of biodiesel and petroleum diesel for use in an urban bus", National Renewable Energy Laboratory (NREL), Colorado, USA, May 1998, pp. 1-314

[16] K. J. Swanson, M. C. Madden, A. J. Ghio, "Biodiesel exhaust: the need for health effects research", Environmental health perspectives, vol. 115, no. 4 , Apr. 2007, pp. 496-499

[17] S. M. Correa, G. Arbilla, G. "Aromatic hydrocarbons emissions in diesel and biodiesel exhaust", Atmospheric Environment, vol. 40, 2006, pp. 6821-6826

[18] R. Steenblik, "Liberalisation of trade in renewable energy and associated technologies: biodiesel, solar thermal and geothermal energy", OECD Trade and Environment working paper no. 1, Apr. 2006, pp. 1-28

[19] H. H. Masjuki, et al., "Experimental evaluation of an unmodified diesel engine using biodiesel with fuel additive", International Forum on Strategic Technology (IFOST), Oct. 2006, pp. 96-99

[20] J. P. Szybist, S. R. Kirby, A. L. Boehman, "NOx emissions of alternative diesel fuels: a comparative analysis of biodiesel and FT diesel", Energy \& Fuels, 2005, vol. 19, pp. 1484-1492

[21] J. Kennedy, "Balancing generation for large scale wind integration", $\mathrm{PhD}$ thesis, Queen's University Belfast, UK, 2008

[22] H. Bauer, K. Dietsche, T. Jager, Diesel-engine management, $4^{\text {th }}$ ed., Plochingen, Germany, Robert Bosch GmbH, 2005

[23] B. Kegl, A. Hribernik, "Experimental analysis of injection characteristics using biodiesel fuel", Energy \& Fuels, 2006, vol. 20, no. 5, pp. $2239-2248$

[24] Reciprocating internal combustion engine driven alternating current generating sets - part 5: generating sets, BS ISO 8528-5:2005

[25] "Control of emissions of air pollution from nonroad diesel engines and fuel", The Federal Register (FR), vol. 69, no. 124, pp. 3900739056, June 2004
[26] "Directive 2004/26/EC of the European Parliamennt and of the Council of $21^{\text {st }}$ April 2004 (amendment to directive 97/68/EC)", Official Journal of the European Communities, L146/1-L146/107

[27] D. B. Snyder, E. G. Washington, A.P. Indrajuana, G. M. Shaver, "Steady-State biodiesel blend estimation via a wideband oxygen sensor", Amer. Control Conf., Jun. 2008, pp. 988 - 993

[28] D. J. McGowan, D. J. Morrow, B. Fox, "Multiple input governor control for a diesel generating set", IEEE Trans. Energy Convers., vol. 23, no. 3, Sep. 2008, pp. 851 - 859

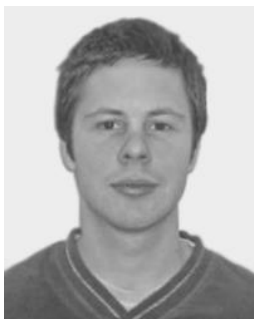

\section{BIOGRAPHIES}

Robert J. Best (M'09, S'07) was born in Belfast, Northern Ireland, in 1980. He received the M.Eng. and Ph.D. degrees from Queen's University Belfast, U.K., in 2004 and 2008, respectively. He is currently a Research Fellow with the Electrical Power and Energy Research Cluster at Queen's University Belfast, with research interests in power system islanding, distributed generation and electric machinery. His placements as an undergraduate were with Northern Ireland Electricity and Helsinki Energy. Dr. Best is a member of the IET.

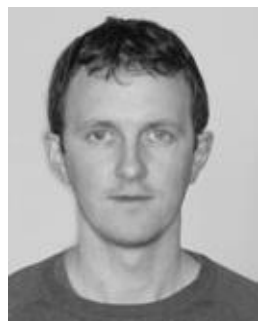

Jason M. Kennedy was born in Ballymena, Northern Ireland, in 1980. He received the M.Eng. and $\mathrm{Ph} . \mathrm{D}$. degrees from Queen's University Belfast, U.K., in 2004 and 2008, respectively. He is currently a Research Fellow with the Electrical Power and Energy Research Cluster at Queen's University Belfast, with research interests in power system operation with high wind penetrations, distributed generation, and transients \& dynamic stability for system with high wind penetrations.

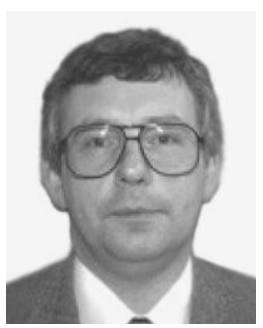

D. John Morrow (M'99) was born in Dungannon, Northern Ireland, in 1959. He received the B.Sc and $\mathrm{Ph} . \mathrm{D}$. degrees from Queen's University Belfast, U.K., in 1982 and 1987, respectively. He is a Reader in electrical engineering at Queen's University Belfast, where he has been since 1987, with research and consulting interests in electric power systems, power system instrumentation, and gen-set controllers. Dr. Morrow is a member of the IET and also a member of the IEEE PES Excitation Systems Subcommittee.

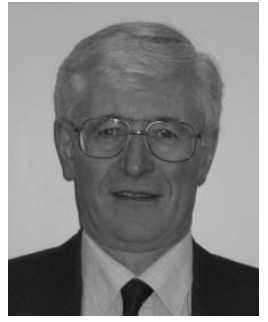

Brendan Fox received the B.Sc. and Ph.D. degrees from Queen's University Belfast (QUB) in 1966 and 1969. Following a period with the Central Electricity Generating Board in Great Britain, he joined the Ulster Polytechnic as a Lecturer in 1972 . He was then appointed to a lectureship at QUB in 1980 . He is now Professor of Power Systems Engineering at QUB. His main research interest is in the integration of wind power on a significant scale. Professor Fox is a member of the IET. 